\title{
Interview with Singapore Film Director Ken Kwek
}

\author{
By Jan Uhde
}

Spring 2013 Issue of KINEMA

\section{INTERVIEW WITH SINGAPORE FILM DIRECTOR KEN KWEK}

Ken Kwek is a Singapore filmmaker whose fresh satirical comedy Sex.Violence.FamilyValues (2012) stirred the relatively calm waters of the city-state's film production. It consists of three stories: "Cartoons," "Porn Masala" and "The Bouncer". In "Cartoons", a mother is called by the kindergarten teacher concerning the drawings of her son; the "Porn Masala" is about the shooting of a pornographic film about a middle-aged Indian man having sex with a young virgin; in "The Bouncer", a nightclub bouncer becomes anxious when he realizes his daughter is about to perform as a pole dancer there. The three stories challenge, through irony and unexpected twists of the plot, some conventional per-ceptions of contemporary Singapore society. Apparently misunderstood by some, the movie was banned in Singapore after its scheduled premiere in October 2012, but was eventually re-released in March 2013.

KINEMA: As a scriptwriter and cinematographer, you are familiar with the odds filmmakers face, especially in Singapore. What made you decide to become a director?

Ken Kwek: I quit my job as a newspaper journalist in 2007, fed up with the culture of media censorship in Singapore. Soon after, theatre director Glen Goei half-jokingly asked me to write him a screenplay as he hadn't made a film since Forever Fever in 1999. I had moved to Michigan in the United States at the time and was struggling to find regular work. Out of desperation, I took up Glen's challenge and camped out for a month at a cheap diner with my laptop. I think Glen was quite surprised when I sent him the screenplay for The Blue Mansion. Then it was my turn to be surprised when he decided to actually shoot it! This was in 2008. I've been writing and directing films ever since.

For your first fiction feature, you chose to do a comedy, not exactly the easiest genre to approach. What was your reason for this choice?

At 47 minutes, Sex.Violence.FamilyValues $(S V F V)$ is not strictly speaking a feature. But it is a comedy. More specifically its three stories are told as different forms of comedy: a dark comedy, a satirical farce, and a dramatic comedy. I wanted my first film (as director) to be something that made people laugh, something that evokes different types of laughter.

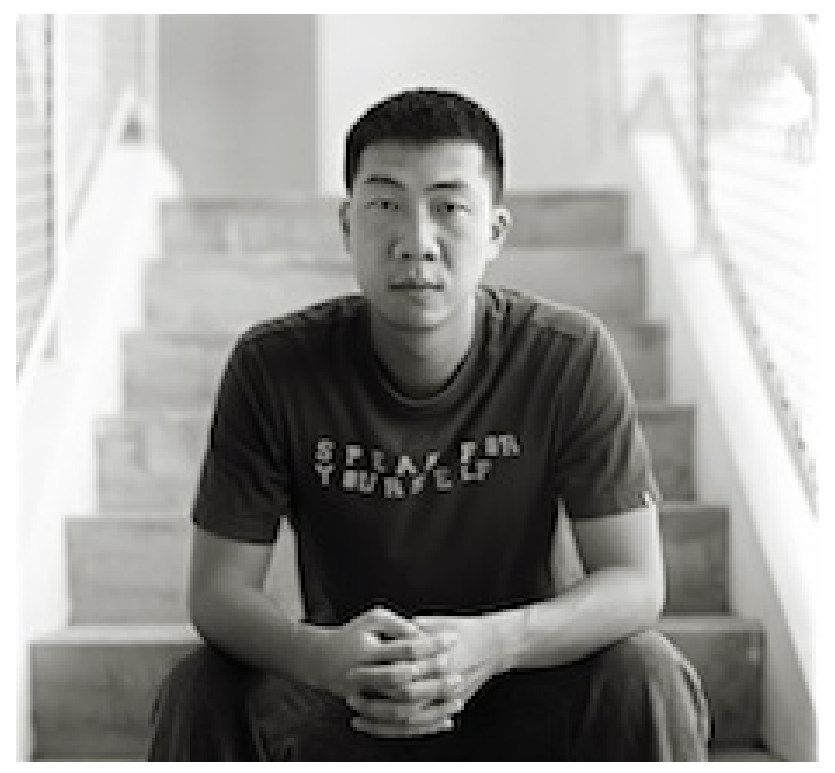

Figure 1: Director Ken Kwek 
Your debut's title, Sex.Violence.FamilyValues, is an ironic contradiction which suggests something about the film's subject matter. Could you comment on this title selection?

Well, no filmmaker sets out to create a boring title! Sex.Violence.FamilyValues is a somewhat cumbersome title, but it hopefully catches people's attention.

SVFV is an omnibus film, a collection of three individual stories. What benefits do you see in this format?

The omnibus format gives a filmmaker scope. It gives him the chance to experiment with vastly different looks, tones and genres within the rubric of a single work. There is of course the challenge of piecing the stories together into a single narrative with a satisfying emotional arc and thematic coherence.

Your film is a satirical comedy. The script makes use of plot twists - in effect each of the three stories involves a certain paradox. Could you comment on the subject matter?

I wouldn't say the stories involve a paradox. Certainly they reveal contradictions and double-standards within the characters portrayed. The stereotypical view of Singapore that both the government and the Western media often propagate is that of a clean, orderly society populated by rather straitlaced urbanites. That is not the Singapore I live in. Singapore is a complicated society, one that is evolving at an incredible rate. There is an increasing tension between the mores of family and society and the desires of the individual. That tension, I find, can be at once painful and ridiculous. So in the third story, for example, we find a liberal Muslim father gagging at his daughter's enthusiasm for pole dancing - a decidedly secular activity. As a parent, the man is in an impossible - and incredibly funny - predicament.

SVFV became the subject of controversy when it premiered in Singapore in October 2012. It was officially released, then banned and eventually allowed to be screened. Would you comment on the following related points?

a) The alleged complaints which caused the authorities to ban the film after it had been given classification

The film was banned in both Singapore and Malaysia. In Singapore, there were alleged complaints about the film' $s$ use of racially offensive language and the portrayal of a porn actress in a school pinafore. As for Malaysia, the report from its Film Censorship Board said the film contained "obscene language and actions that ridicules and insults local culture." [Editor's note: The film was to be shown at the Asean International Film Festival in Kuching, Malaysia (March 28-30, 2013), but it was banned by the Malaysian Censors Board a few days before the festival began.]

b) Your reaction and steps taken after the film was banned

I was not surprised about the ban in Malaysia, a relatively conservative Muslim country. I was a little put off and put out by the ban in Singapore. It smacked of double standards by the authorities, who had passed far more controversial films in the past, and who had declared that it was moving away from cuts in favour of classification. I appealed against the ban, successfully, but was given a higher classification (R21 Restricted to age 21 and over) and ordered to excise two lines of dialogue in the film deemed to be "racially offensive." I was not pleased with this result, but had to live with it. Fortunately, the edits did not seem to deter Singaporeans from watching the film. We had a good theatrical run with many sold out sessions.

Although made in an accessible style, Sex.Violence.FamilyValues is not a mainstream film Singapore audiences are familiar with. How was its reception in Singapore?

We had a limited, single-print release in Singapore. Our distributor Cathay had originally planned to give us just one screening per day for a single week in a 77-seat theatre. But we started selling out days in advance and were eventually given four sessions daily and in a bigger theatre. The run was also extended from one to three weeks.

How was the response in other Asian countries and the rest of the world?

The component stories of Sex.Violence.Family Values have been screened at more than a dozen international festivals in the US, Europe, India, Korea and Australia. The film's second story, "Porn Masala" won the Audience Choice Award (Short Film) at the Gotham Screen Film Festival in New York and was nominated for Best Comedy at the Super Shorts Film Festival in London. The film has since been picked up by Singapore cable channel MioTV, iTunes as well as an American distributor. 


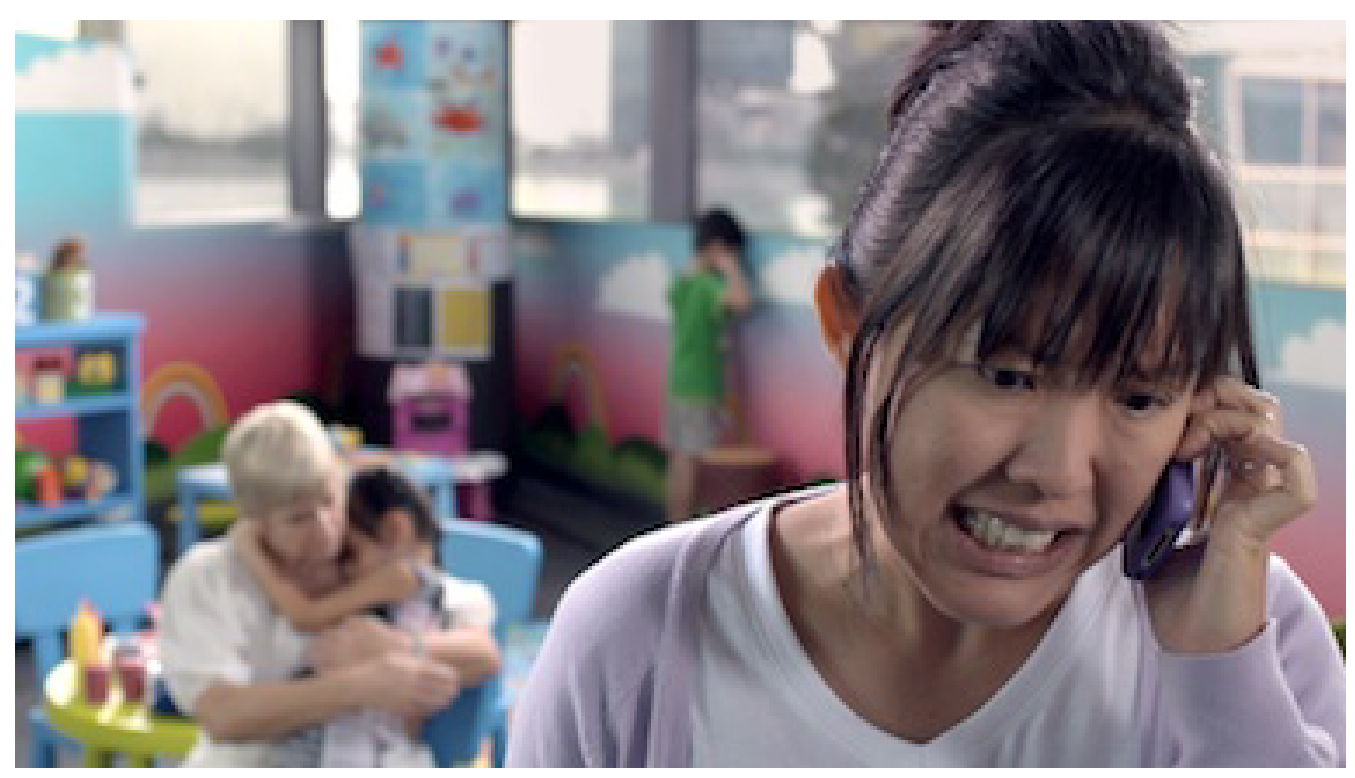

Figure 2: Serene Chen in $S V F V$

For critics' reception of the film, please see also: http://www.sindie.sg/2013/03/review-sex-violence-familyvalues.html and http://www.svfv.com.sg/reviews

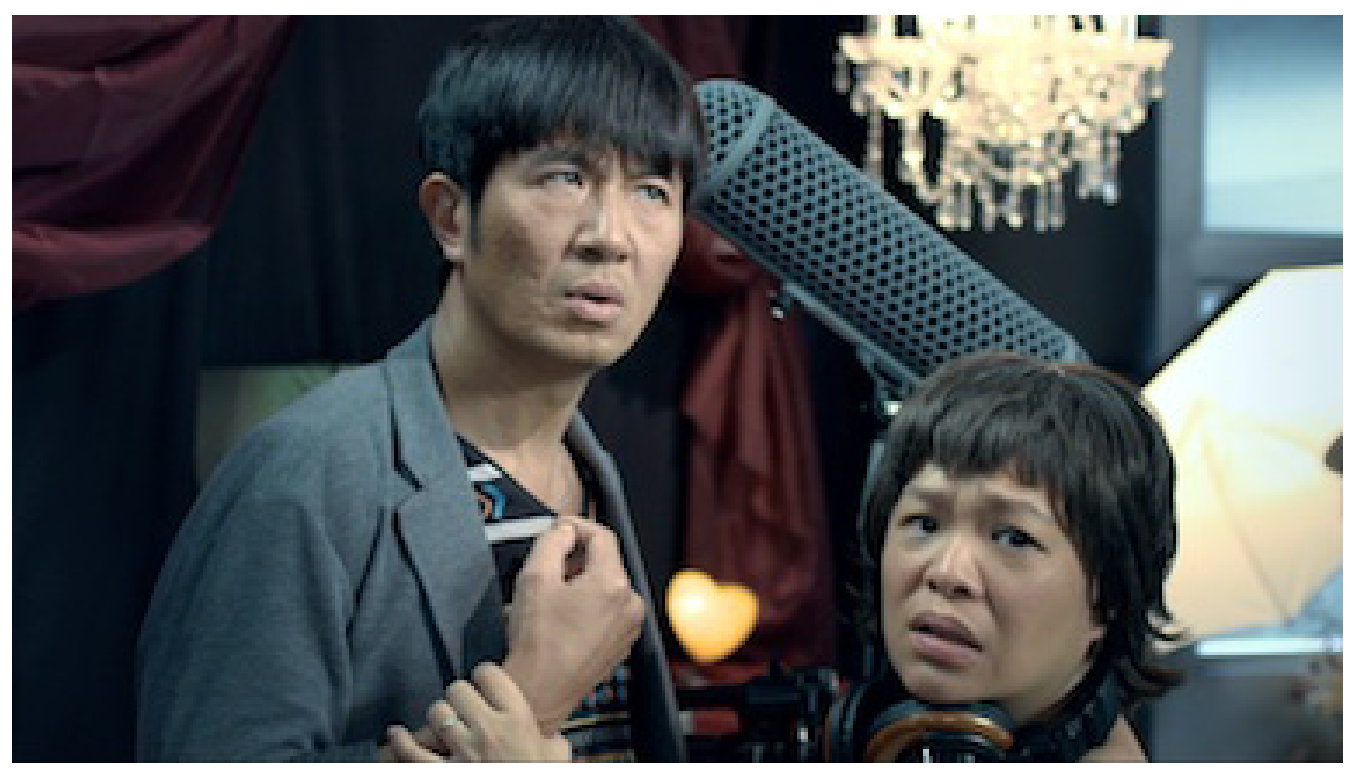

Figure 3: Adrian Pang and Pam Oei in $S V F V$

Any information about your film's budget and funding, institu- tional and private support?

Our budget was USD 80,000. SVFV was produced and financed by The Butter Factory, a Singapore entertainment company.

The SVFV delivers impressive acting performances, better than the average Singapore made feature. How did you manage to obtain accomplished performances from your cast?

I am a great believer in Sidney Lumet's approach to directing. For $S V F V$, I was adamant that the actors be prepared for this film as if they were preparing for a stage play. We rehearsed and improvised in a studio for 
several weeks before the cameras rolled. I also made the actresses playing pole dancers do a night of erotic dance performances at an actual nightclub before bringing them on set. I don't believe in 'over-rehearsing'. I think if actors know their characters very well before hand, then there is a higher chance of spontaneous magic happening on set when the cameras roll.

\section{What are your future plans?}

I've written a screenplay called Trafficker, a drama about two brothers blackmailed into smuggling drugs, which is set to be directed later this year by the British cinematographer, Larry Smith.

\section{Anything you would like to tell KINEMA readers about Singapore cinema?}

The most popular joke about Singapore in the West is that its people can't even buy chewing gum from the supermarket. But the fact is, chewing gum loses its taste. The rest of the world should take a closer look at the good stuff that Singaporeans are really sinking their teeth into.

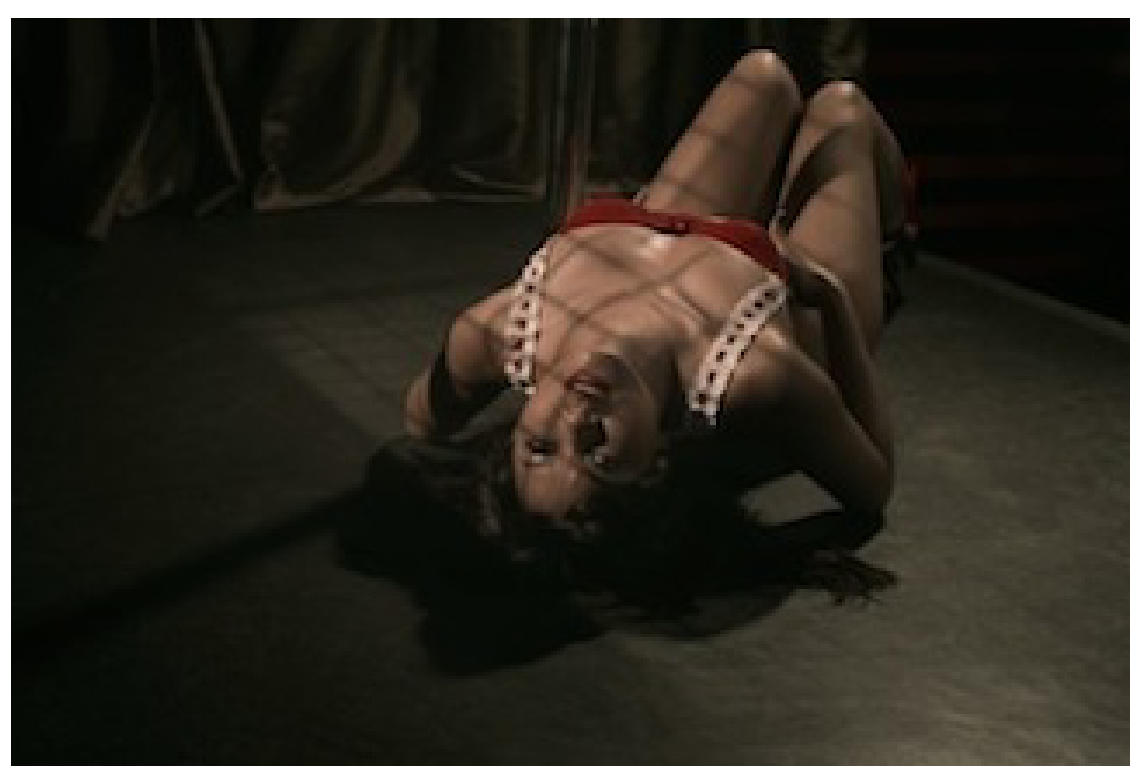

Figure 4: Sylvia Ratonel in $S V F V$

\section{Author Information}

Jan UHDE is Professor Emer. (Film Studies) at the University of Waterloo, Ontario, Canada. Born in Brno, Czech Republic. Graduated (MA) from the Faculty of Arts, Masaryk University, Brno; PhD received at the University of Waterloo, Ontario, Canada. He taught at the University of Waterloo (1970-2012) where he founded a General and Honours BA program in Film Studies at the Department of Fine Arts.

Publications: Latent Images: Film in Singapore Second edition, with Yvonne Ng Uhde (Ridge Books, National University Press of Singapore, 2010); Latent Images: Film in Singapore, with Yvonne Ng Uhde (Oxford University Press, 2000); Latent Images: Film in Singapore CD-ROM (2003, co-author); Vision and Persistence: Twenty Years of the Ontario Film Institute (University of Waterloo Press, 1990) and Ontario Film Institute Programming Activities Index 1969-1989 (Toronto: Ontario Science Centre, 1990). He co-edited the Place in Space: Human Culture in Landscape (Proceedings from the Second International Conference of the Working Group "Culture and Landscape" of the International Association of Landscape Ecology, Pudoc Scientific Publishers, Wageningen, Holland, 1993). Jan Uhde has published articles and reviews in several countries (including Canada, USA, Germany, Italy), participated in international juries at film festivals and presented papers at international conferences in North America and Europe. In 1998/99, he was a visiting researcher at the School for Film and Media Studies, Ngee Ann Polytechnic, Singapore. 
His professional and research interests focus on Singapore cinema; the identification and distancing mechanisms of the film viewer; the non-authored modifications and manipulation of films; and specific aspects of film history, including the Central European cinema.

He founded KINEMA in 1993. 